\title{
Enfermería Nefrológica y su posición en el SCimago Journal \& Country Rank (SJR)
}

\author{
Rodolfo Crespo-Montero \\ Director Enfermería Nefrológica
}

Como citar este artículo:

Crespo-Montero R. Enfermería Nefrológica y su posición en el SCimago Journal \& Country Rank (SJR).

Enferm Nefrol. 2019 Jul-Sep;22(3):221-2

El SCImago Journal \& Country Rank es el portal de evaluación de revistas científicas basado en la información contenida en la Base de Datos Scopus (Elsevier) ${ }^{1}$. La plataforma debe su nombre al SCImago Journal Rank (SJR) Indicator, desarrollado por el grupo de investigación Scimago. El indicador SJR se realiza sobre el cálculo de las citas recibidas por las revistas en un periodo de 3 años, otorgando un peso mayor a las citas procedentes de revistas de alto prestigio y restringe las autocitas para que sólo consti-

\begin{tabular}{|l|c|c|c|c|c|}
\hline Año & SJR & Posición & Citas recibidas & Auto-citas & $\%$ \\
\hline $\mathbf{2 0 1 1}$ & 0,187 & $30 / 54$ & 14 & 12 & 86 \\
\hline $\mathbf{2 0 1 2}$ & 0,143 & $36 / 55$ & 14 & 8 & 57 \\
\hline $\mathbf{2 0 1 3}$ & 0,188 & $31 / 55$ & 31 & 29 & 94 \\
\hline $\mathbf{2 0 1 4}$ & 0,188 & $31 / 56$ & 17 & 6 & 35 \\
\hline $\mathbf{2 0 1 5}$ & 0,142 & $36 / 55$ & 21 & 8 & 38 \\
\hline $\mathbf{2 0 1 6}$ & 0,133 & $42 / 56$ & 26 & 14 & 54 \\
\hline $\mathbf{2 0 1 7}$ & 0,198 & $33 / 57$ & 26 & 18 & 69 \\
\hline $\mathbf{2 0 1 8}$ & 0,150 & $41 / 56$ & 13 & 4 & 31 \\
\hline
\end{tabular}

Posición: lugar ocupado por Enfermería Nefrológica en la categoría de Enfermería Avanzada y Especializada.

$\%$ : porcentaje de auto-citas respecto al total de citas recibidas.

Fuente: SCImago Journal \& Country Rank.

tuyan el $33 \%$ del cómputo². Es decir,

el SJR de 2018 corresponde a las citas recogidas en ese año, de los artículos publicados en los años 2015, 2016 y 2017. Ni que decir tiene que este índice es el más importante que recibe Enfermería Nefrológica a nivel internacional, dentro de la materia Enfermería y la categoría Enfermería Avanzada y Especializada.

Recientemente se ha publicado el SCImago Journal Rank (SJR) correspondiente a 2018, y lamentablemente hemos sufrido un retroceso en el valor de este índice, con el consiguiente retroceso en la posición que ocupaba Enfermería Nefrológica en 2017 en la categoría de Enfermería Avanzada y Especializada, razón por la cual he creído conveniente analizar el dato. Para ilustrar con más nitidez la evolución de este índice en Enfermería Nefrológica, hemos elaborado una tabla con el SJR y otros datos, directamente relacionados con la elaboración del mismo, desde el año 2011 hasta el 2018 recogidos del portal de SCImago Journal \& Country Rank ${ }^{3}$.

Como podemos apreciar en esta Tabla, el SJR ha oscilado en un rango de 0,133 a 0,198 y es precisamente lo que marca la posición dentro de las 54-57 revistas de esta categoría, y como es lógico, cuando el SJR desciende, lo hace proporcionalmente la posición de nuestra Revista respecto al resto de revistas de su categoría. Esta posición es la que determina el Cuartil (Q), y aunque Enfermería Nefrológica continua en el Q3, en el año 2018, se ha quedado a un puesto del Q4, lo cual es preocupante, teniendo en cuenta que siempre ha estado en el Q3 en la categoría de Enfermería Avanzada y Especializada, tal como mostró el análisis de la evolución de la Revista que realizaba Cobo-Sánchez y cols $^{4}$; y sobre todo, ocurre cuando desde el equipo de Dirección se tenía la impresión de haber mejorado la calidad de la Revista en los últimos 2-3 años.

Analizar las causa de este retroceso es casi imposible dada la complejidad en el cálculo utilizado en la métrica SJR, pero si podemos reflexionar sobre las pocas citas recibidas en 2018, aunque curiosamente es el año con menor porcentaje de auto-citas. En efecto, como podemos observar en los datos de las citas, es difícil encontrar una relación matemática entre el nú- 
mero de citas recibidas con el valor del SJR, por lo que tampoco cabe inferir que el porcentaje de auto-citas es el factor que más influye en el índice (obsérvese que en el año 2013, las auto-citas supusieron el $94 \%$ del total de citas recibidas y sin embargo, el valor de SJR fue el segundo más alto de los años recogidos). Tampoco parece tener relación directa con el número total de citas..., depende evidentemente de la calidad, contenido y originalidad de los documentos publicados, es decir, del interés que estos artículos despiertan en otros autores.

A este respecto, poco podemos hacer desde la dirección de la Revista, pues el que otros autores citen los documentos publicados en Enfermería Nefrológica no depende de nosotros, obviamente; pero si tenemos la responsabilidad de mejorar dos aspectos clave para intentar aumentar el número de citas de la Revista: el primero, mejorar los criterios de calidad "formales" de los documentos, como la sintaxis del leguaje científico, la estructura del documento de acuerdo a las Normas de Publicación o la utilización de términos MeSH (descriptores) en las palabras clave. La originalidad y despertar interés científico, corresponde a los autores de los originales. Se necesitará, por tanto, un esfuerzo aún mayor por parte de revisores y autores por adaptarse a esta nueva realidad de exigencia.

En segundo lugar, es imprescindible, mejorar la inmediatez y visibilidad de los artículos. Sobre la inmediatez es difícil actual, aunque se están dando algunos pasos en este sentido que pueden mejorar la misma, como son disponer con antelación de los artículos de un número y publicarlos en Pre-impresión, y tener un DOI (Digital Object Identifier) propio, pues hasta ahora la asignación de este D0I se hacía a través de Scielo España lo cual suele retrasar la aparición de los artículos en las bases de datos. Respecto a la visibilidad, solo comentar que es imposible aumentarla sin estar en la base de datos Medline, objetivo que queremos abordar este año, sometiendo a Enfermería Nefrológica a una primera evaluación, que sin riesgo de equivocarnos, será negativa, pero ayudará para conseguirlo en la segunda.

¡Qué tengáis un 44 Congreso de la SEDEN con mucho "cientifismo"!

\section{Bibliografía}

1. SCImago Journal \& Country Rank. [Consultado el 07-08-2019]. Disponible en: https://www.scimagojr.com/.

2. Biblioteca de la Universidad de Sevilla. Factor de Impacto: Factor de Impacto con Scopus. [Consultado el 08-08-2019]. Disponible en: http://guiasbus. us.es/factordeimpacto/scopus.

3. SCImago Journal \& Country Rank. Journal Rankings. Enfermería Nefrológica. [Consultado el 07-08-2019]. Disponible en: https://www.scimagojr.com/journalsearch.php?q=21100416607\&ti$\mathrm{p}=\mathrm{sid} \&$ clean $=0$.

4. Cobo-Sánchez JL, Ochando-García A, Blanco-Mavillard I, Cirera-Segura F, Crespo-Montero R, Casas-Cuesta R. Análisis del impacto de la producción científica de la revista Enfermería Nefrológica entre 1998 y 2017. Enferm Nefrol. 2018;21(4):34958.

Este artículo se distribuye bajo una Licencia Creative Commons Atribución-NoComercial 4.0 Internacional. https://creativecommons.org/licenses/by-nc/4.0/ 